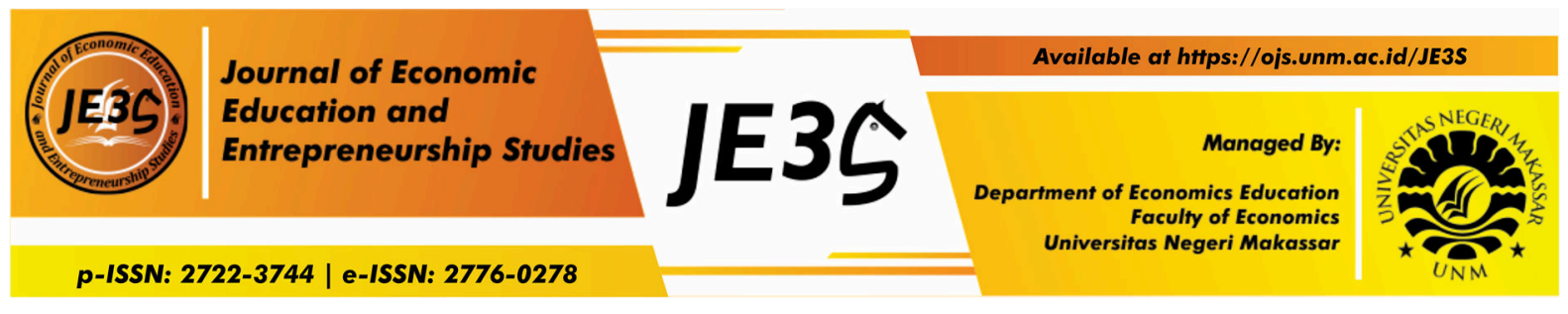

\title{
Analisis Pengaruh Kreativitas Kewirausahaan terhadap Kesiapan Bekerja Siswa
}

\author{
Nurhikmawati $^{1 *}$, Thamrin Tahir ${ }^{2}$, Muhammad Hasan $^{3}$ \\ ${ }^{1,2,3}$ Program Studi Pendidikan Ekonomi, Fakultas Ekonomi, Universitas Negeri Makassar
}

\begin{tabular}{l}
\hline Article History \\
\hline Received May 20, 2020 \\
Approved June 20, 2020 \\
Published June 30, 2020
\end{tabular}

\begin{tabular}{l}
\hline \multicolumn{1}{c}{ Keywords } \\
\hline Kreativitas Kewirausahaan, Kesiapan \\
Bekerja
\end{tabular}

\begin{tabular}{c}
\hline JEL Classification \\
\hline O31, L26, A20 \\
\hline
\end{tabular}

\begin{tabular}{l}
\hline \multicolumn{1}{c}{ How to Cite } \\
\hline Nurhikmawati, Tahir, T., \& Hasan, M. \\
2020. Analisis Pengaruh Kreativitas \\
Kewirausahaan Terhadap Kesiapan \\
Bekerja Siswa. Journal of Economic \\
Education and Entrepreneurship Studies, \\
1(1), 16-23.
\end{tabular}

\begin{abstract}
The purpose of this study is to determine the effect of entrepreneurial creativity on student readiness (SMKN 1 Sinjai). This type of research is quantitative research. Data obtained through the distribution of questionnaires with a Likert scale. The population in this study were all class XI and XII majors online business and marketing of SMKN 1 sinjai totaling 72. The results of this study indicate that creativity has a significant effect on the value of Sig. $=0,000<0.05$ which means it meets the significant criteria, while the T-count is 10.845> 1.666 which means it rejects null hypothesis and accept alternative hypotheses for testing both variables Based on the regression test it is known that the creativity variable has a contribution of 62.7 percent to work readiness, while based on the descriptive test it can be concluded that work readiness of students has not been able to form optimally that there are still 16 students out of 72 students whose work readiness is still low.
\end{abstract}

\footnotetext{
*Nurhikmawati

Jl. Raya Pendidikan Kampus Fakultas Ekonomi UNM

Kota Makassar, Propinsi Sulawesi Selatan, Negara Indonesia, Kode Pos 90222

e-mail: nurhikmaarifin05@gmail.com
}

(C) 2020 Universitas Negeri Makassar

\section{PENDAHULUAN}

Pengangguran merupakan salah satu permasalahan penting di Indonesia yang sampai saat ini masih saja terus bertambah, disebabkan tidak adanya keseimbangan antara jumlah angkatan kerja dengan lapangan kerja yang tersedia serta minimnya kompetensi keahlian yang dimiliki sumber daya manusianya, data angka pengangguran terbuka berdasarkan data BPS pada tahun 2018 yaitu berjumlah 6,87 juta, padahal pengangguran mempunyai banyak dampak negatif diantaranya dapat merugikan negara 
karena produktivitas negara rendah, pendapatan perkapita masyarakat rendah serta jumlah kemiskinan akan bertambah, oleh karena itu harus diatasi salah satu caranya adalah melalui pendidikan (Wibowo, 2018). Pendidikan adalah solusi yang dapat dijadikan tolak ukur kualitas dari suatu negara sebab pendidikan merupakan wahana untuk meningkatkan dan mengembangkan kualitas sumber daya manusia.

Sekolah Menengah Kejuruan (SMK) adalah sekolah yang dirancang oleh pemerintah sebagai solusi untuk mengurangi pengangguran, hal ini didukung oleh Peraturan Pemerintah Nomor 29 Tahun 1990 yang memuat amanat tentang pendidikan dan pengembangan kemampuan siswa untuk melaksanakan pekerjaan sesuai dengan bidang kompetensi yang dimiliki. Kurikulum SMK dibuat agar peserta didik siap untuk langsung bekerja di dunia kerja maupun membuka usaha, untuk mendukung tujuan tersebut maka diadakan program prakerin dan mata pelajaran kewirausahaan untuk peserta didik sebagai dasar keahlian, keahlian tersebut yang menjadi pembeda dengan siswa Sekolah Menengah Atas dan Madrasah Aliyah (Setiawan, 2016). Tujuan SMK berdasarkan Peraturan Pemerintah Republik Indonesia Nomor 19 Tahun 2005 tentang Standar Nasional Pendidikan Pasal 26 ayat 3 yaitu meningkatkan kecerdasan, pengetahuan, kepribadian, akhlak mulia serta keterampilan untuk hidup mandiri dan mengikuti pendidikan lebih lanjut sesuai dengan kejuruannya. Hidup mandiri yang dimaksud bukan hanya mengisi lowongan kerja di dunia industri tetapi juga bekerja mandiri menjadi wirausaha.

Jurusan Bisnis Daring dan Pemasaran adalah salah satu jurusan yang memiliki prospek kerja yang bagus bagi lulusannya dengan berbekal kompetensi dasar keahlian yang meliputi mata pelajaran Bisnis Online, Penataan Produk, Administrasi Transaksi, Pengelolaan Bisnis Ritel serta Produk Kreativitas dan Kewirausahaan. Sebenarnya berdasarkan kurikulum 2013 revisi 2017 semua program kejuruan di SMK dituntut untuk memiliki kompetensi kewirausahaan dengan diterbitkannya SK Dirjen Dikdasmen Nomor 130/D/KEP/KR/2017. Perencanaan Bisnis dan Komunikasi Bisnis merupakan dasar dari program keahlian jurusan Bisnis Daring dan Pemasaran yang memang sejalan dengan kompetensi kewirausahaan khususnya indikator kreativitas maka bisa disimpulkan bahwa jurusan ini memang tidak bisa dipisahkan dari kompetensi tersebut. Kompetensi adalah kemampuan seseorang untuk melaksanakan sesuatu yang dibina melalui pendidikan dan pengalaman. Kompetensi kewirausahaan diartikan sebagai kompetensi untuk menciptakan sesuatu melalui jiwa kreativitas yang menjadikan mereka berani untuk menjadi pelaku usaha. Seorang wirausaha adalah orang yang mampu menciptakan produk yang bernilai tambah, untuk menciptakan nilai tambah ini melalui jiwa kreativitas. Terdapat 4 unsur pokok yang dimiliki seorang wirausaha yaitu kemampuan (pengetahuan dan keterampilan), keberanian (emosi dan mental), keteguhan hati (motivasi) dan kreativitas, kesuksesan dari seorang wirausaha selalu tidak terpisahkan dari kreativitas.

Wirausaha tercipta karena adanya daya kreativitas yang tinggi, kewirausahaan berintikan kreativitas, kreativitas dapat diartikan sebagai kemampuan untuk melakukan eksplorasi atau pembaruan yang melahirkan ide atau gagasan, kemampuan ini sebenarnya sudah dimiliki dari lahir namun harus terus diasah dan dikembangkan melalui pengembangan atau pendidikan yang tepat (Hendro, 2011). Namun, berdasarkan fakta bahwa pengangguran terbesar di Indonesia justru berasal dari lulusan SMK, hal tersebut disebabkan oleh beberapa faktor diantaranya sempitnya lapangan kerja yang tersedia, minimnya kompetensi keahlian yang dimiliki lulusannya dan kesiapan bekerja dari lulusannya itu sendiri (Ratnaningsih, Kustanti, Prasetyo \& 
Fauziah 2017). Sejalan dengan pendapat di atas Rifai dan Sucihatiningsih (2016) melakukan penelitian yang berisi bahwa tingkat pengangguran terbuka menurut pendidikan didominasi oleh sekolah menengah kejuruan (SMK) yaitu 12,65 persen, disusul sekolah menengah atas sebesar 10,32 persen, diploma 7,54 persen, sarjana 6,40 persen, sekolah menengah pertama 6,22 persen, dan sekolah dasar ke bawah 2,74 persen yang data nya bersumber dari BPS tahun 2015.

Pada Agustus 2018 jika dilihat dari tingkat pendidikan, TPT untuk Sekolah Menengah Kejuruan (SMK) masih mendominasi diantara tingkat pendidikan yang lain, yaitu sebesar 11,24 persen. Jumlah pengangguran tersebut menggambarkan bahwa kualitas SDM lulusan SMK masih belum bisa bersaing untuk mengisi lowongan pekerjaan yang tersedia (Umayah, 2017). Berdasarkan observasi awal peneliti berikut ini adalah tabel keadaan lulusan SMKN 1 Sinjai Jurusan Bisnis Daring dan Pemasaran angkatan 2013 yang berjumlah 42 orang hanya 8 orang yang bekerja dan sisanya terbagi atas kuliah dan tidak bekerja yang terdiri setengah menganggur dan terbuka. Untuk memenuhi tuntutan dunia kerja serta permasalahan rendahnya kualitas sumber daya manusia diperlukan adanya kesiapan kerja yang matang karena kesiapan adalah pondasi utama seseorang untuk melakukan suatu pekerjaan, sebab kesiapan kerja akan menentukan maksimal atau tidaknya hasil pekerjaan seseorang (Harjanto, 2013).

Berdasarkan tujuan dari SMK di atas dan fenomena pengangguran lulusan SMK, peneliti ingin mengetahui apakah kreativitas kewirausahaan yang dimiliki siswa mampu berpengaruh terhadap kesiapan mereka untuk bekerja, baik kompetensi yang dimiliki secara alami maupun kompetensi yang diasah oleh guru di sekolah melalui teori dan praktek. Berdasarkan pada teori hipotesis yang dirumuskan yaitu diduga terdapat engaruh antara kreativitas terhadap kesiapan bekerja siswa, yang selanjutnya diuji kebenarannnya dalam penelitian.

Merujuk dari berbagai penelitian terdahulu yang relevan dengan penelitian ini dapat disimpulkan bahwa banyak faktor yang mempengaruhi kesiapan bekerja pada siswa SMK, diantaranya yaitu minat kerja, prakerin, kepribadian, pengetahuan/pengalaman wirausaha, pelaksanaan kegiatan business centre dan motivasi memasuki dunia usaha. Dalam penelitian ini peneliti akan melihat kesiapan bekerja siswa SMK melalui kompetensi kewirausahaan indikator kreativitas dengan melihat sub indikator pada saat proses pembelajaran yang berkaitan dengan kompetensi kewirausahaan indikator kreativitas, melalui praktek kewirausahaan/class alfamidi serta melalui praktek kerja industri.

\section{METODE}

Penelitian korelasi merupakan jenis penelitian yang digunakan untuk melihat apakah kreativitas kewirausahaan berpengaruh terhadap kesiapan bekerja siswa jurusan bisnis daring dan pemasaran di smkn 1 sinjai. pendekatan yang digunakan yaitu pendekatan metode kuantitatif dimana hasil penelitian akan diwujudkan ke dalam bentuk angkaangka dan dianalisis secara statistik. Adapun desain penelitian yang digunakan adalah deskriptif kuantitatif, karena pengujian variabel yang akan dilakukan menekankan pada pengujian teori melalui pengukuran variabel dengan angka dan analisis data yang dipakai menggunakan prosedur statistik dengan bantuan SPSS.

SMKN 1 Sinjai berlokasi di Jalan Tekukur No. 1, Kelurahan Biringere, Kecamatan Sinjai Utara, Kabupaten Sinjai. Berdiri tanggal 5 juli 1969 dengan Nomor SK 120/UK.3/1969 dengan nama SMEA Negeri Sinjai, sekolah ini merupakan sekolah 
menengah kejuruan tertua sekaligus terfavorit di kabupaten Sinjai yang saat ini bernama SMKN 1 Sinjai. Teknik penarikan sampel yang digunakan adalah simple random sampling yaitu teknik dengan seluruh anggota dalam populasi memiliki peluang dan kesempatan yang sama untuk dipilih dengan cara yang acak. Apabila populasi yang sedang diteliti kurang dari 100 orang maka semua populasi (100\%) di ambil sebagai sampel, tetapi jika lebih dari 100 orang maka diambil $10 \%-25 \%$ atau $20 \%-25 \%$ dari jumlah populasinya (Arikunto, 2008). Karena jumlah populasi dalam penelitian ini hanya 72 orang maka 100\% jumlah populasi yang ada di kelas XI dan XII jurusan Bisnis Daring dan Pemasaran di jadikan sebagai responden.

Jenis data menurut sumbernya dalam penelitian ini terdiri atas data primer dan data sekunder. Data primer ini diperoleh melalui penyebaran kuesioner kepada siswa untuk mendapatkan pendapat mereka. Sedangkan yang termasuk sumber data primer dalam penelitian ini adalah dokumen atau data-data yang terdapat pada SMKN 1 Sinjai yang meliputi profil sekolah, data grafik siswa, kurikulum jurusan bisnis daring dan pemasaran dan data-data lain yang berkaitan dengan siswa. Analisis instrumen penelitian digunakan dalam penelitian ini terdiri dari uji validitas dan realibilitas.

\section{HASIL DAN DISKUSI}

Berdasarkan hasil uji analisis data, disajikan data berdasarkan masing-masing jenis uji dan untuk memudahkan dalam memahami hasil penelitian maka dibuatkan tabel tingkat penggolongan untuk kedua variabel.

Tabel 1. Penggolongan Kategori Kreativitas

\begin{tabular}{ccccc}
\hline No. & Interval Kelas & Frekuensi & Persentase (\%) & Kategori \\
\hline 1. & $>103$ & 22 & 30.6 & Tinggi \\
2. & $85-103$ & 40 & 55.6 & Sedang \\
3. & $<85$ & 10 & 13.9 & Rendah \\
\hline & Jumlah & 72 & 100 & \\
\hline
\end{tabular}

Sumber: Hasil Olah Data, 2020

Berdasarkan hasil perhitungan analisis deskriptif pada Tabel 1 maka dapat diketahui bahwa pengaruh kreativitas berada pada kategori sedang yaitu 40 responden atau setara dengan 55.6 persen dilihat dari indikator proses pembelajaran, Class Alfamidi dan praktek kerja industri.

Tabel 2. Penggolongan Kategori Kesiapan Bekerja

\begin{tabular}{ccccc}
\hline No. & Interval Kelas & Frekuensi & Persentase (\%) & Kategori \\
\hline 1. & $>27$ & 17 & 23.6 & Tinggi \\
2. & $27-22$ & 39 & 54.2 & Sedang \\
3. & $<22$ & 16 & 22.2 & Rendah \\
\hline & Jumlah & 72 & 100 &
\end{tabular}

Sumber:Hasil Olah Data Angket, 2020 
Berdasarkan Tabel 2 data yang diperoleh dari angket kesiapan bekerja maka dapat diketahui bahwa pengaruh kesiapan bekerja berada pada kategori sedang yaitu 39 responden atau setara dengan 54.2 persen dilihat dari indikator kesiapan mengisi lowongan kerja yang tersedia dan menjadi wirausaha. Berdasarkan pembahasan tersebut dapat disimpulkan bahwa kesiapan bekerja siswa memang belum tinggi, dengan 72 responden masih terdapat 16 orang yang menjawab belum siap sepenuhnya untuk bekerja atau kesiapan bekerjanya masih berada pada kategori rendah padahal seharusnya semua lulusan sudah memiliki kesiapan bekerja yang matang.

Tabel 3. Hasil Analisis Uji Linearitas

\begin{tabular}{|c|c|c|c|c|c|c|c|}
\hline & & & $\begin{array}{c}\text { Sum of } \\
\text { Squares }\end{array}$ & Df & $\begin{array}{l}\text { Mean } \\
\text { Square }\end{array}$ & $\mathrm{F}$ & Sig. \\
\hline \multirow{5}{*}{$\begin{array}{l}\text { Kesiapan } \\
\text { Bekerja* } \\
\text { Kreativitas }\end{array}$} & \multirow{3}{*}{ Between Groups } & (Combined) & 584.569 & 33 & 17.714 & 5.311 & .000 \\
\hline & & Linearity & 445.931 & 1 & 445.931 & 113.691 & .000 \\
\hline & & $\begin{array}{l}\text { Deviation } \\
\text { from } \\
\text { Linearity }\end{array}$ & 138.638 & 32 & 4.336 & 1.299 & .219 \\
\hline & Within Groups & & 126.750 & 38 & 3.336 & & \\
\hline & Total & & 711.319 & 71 & & & \\
\hline
\end{tabular}

Sumber: Hasil Olah Data, 2020

Berdasarkan data pada Tabel 3 yang menunjukkan bahwa deviation from linearity signifikannya adalah sebesar 0.219 dengan kaidah yang digunakan untuk deviation from linearity adalah $\mathrm{p}>0.05$. Selanjutnya pada linearity signifikannya adalah 0,000 , dimana kaidah yang digunakan adalah $\mathrm{p}<0.05$. Berdasarkan penjelasan tersebut dapat disimpulkan bahwa kreativitas dengan kesiapan bekerja adalah linear, sehingga dapat diartikan bahwa hubungan antara Kreativitas (X) terhadap Kesiapan Bekerja (Y) mempunyai arah yang positif.

Tabel 4. Hasil Analisis Uji Hipotesis (t)

\begin{tabular}{|c|c|c|c|c|c|c|}
\hline \multirow{2}{*}{ Model } & \multicolumn{2}{|c|}{$\begin{array}{l}\text { Unstandardized } \\
\text { Coefficients }\end{array}$} & \multirow{2}{*}{$\begin{array}{c}\begin{array}{c}\text { Standardized } \\
\text { Coefficients }\end{array} \\
\text { Beta }\end{array}$} & \multirow[t]{2}{*}{$\mathrm{T}$} & \multirow{2}{*}{ Sig. } & \\
\hline & $\mathrm{B}$ & Std. Error & & & & \\
\hline (Constant) & 5544 & 2.161 & & .252 & & .802 \\
\hline Kreativitas & 244 & .022 & .792 & 10.845 & & .000 \\
\hline
\end{tabular}

a. Dependent Variable: Kesiapan Bekerja

b. Predictors: (Constant), Kreativitas

Sumber: Hasil Olah Data, 2020

Merujuk pada uji hipotesis Tabel 4 terbukti bahwa terdapat pengaruh signifikan antara kreativitas dengan kesiapan bekerja dari hasil perhitungan T-hitung sebesar 10,845 > 1,666 maka $\mathrm{H}_{\mathrm{a}}$ diterima dan $\mathrm{H}_{0}$ ditolak. Hasil dari penelitian ini menunjukkan 
bahwa kreativitas memberikan pengaruh pada kesiapan bekerja siswa kelas XI dan XII jurusan BDP SMKN 1 Sinjai.

Tabel 5. Hasil Analisis Regresi Sederhana

\begin{tabular}{|c|c|c|c|c|}
\hline \multicolumn{5}{|c|}{ Model Summary } \\
\hline Model & $\mathrm{R}$ & $\mathrm{R}$ Square & $\begin{array}{c}\text { Adjusted R } \\
\text { Square }\end{array}$ & $\begin{array}{l}\text { Std. Error of the } \\
\text { Estimate }\end{array}$ \\
\hline 1 & $.792^{\mathrm{a}}$ & .627 & .622 & 1.94712 \\
\hline
\end{tabular}

a. Predictors: (Constant), Kreativitas

b. Dependent Variable: Kesiapan Bekerja

Sumber: Hasil Olah Data Angket, 2020

Berdasarkan Tabel 5 diketahui Nilai R merupakan simbol dari koefesien korelasi 0.792. Nilai dapat diinterprestasikan dengan kriteria 0,75-0,99 berada pada kategori sangat kuat. Melalui tabel 4 dapat diperoleh nilai R Square atau koefesien determinasi yang menunjukkan seberapa bagus model regresi yang dibentuk oleh interaksi variabel bebas dan variabel terikat dengan nilai koefisien determinasi sebesar 0,627 artinya bahwa pengaruh variabel kreativitas terhadap kesiapan bekerja

Tabel 6. Hasil Uji Determinasi

Model Summary ${ }^{b}$

\begin{tabular}{llccc}
\hline Model & $\mathrm{R}$ & $\mathrm{R}$ Square & $\begin{array}{c}\text { Adjusted R } \\
\text { Square }\end{array}$ & $\begin{array}{c}\text { Std. Error of the } \\
\text { Estimate }\end{array}$ \\
\hline 1 & $.792^{\mathrm{a}}$ & .627 & .622 & 1.94712 \\
\hline
\end{tabular}

a. Predictors: (Constant), Kreativitas

b. Dependent Variable: Kesiapan Bekerja

Sumber: Hasil Olah Data, 2020

Berdasarkan Tabel 6 maka diperoleh nilai korelasi variabel kreativitas 0,792 hal ini menunjukkan bahwa hubungan kreativitas terhadap kesiapan bekerja sebesar 0,792 persen artinya sangat kuat. Sedangkan nilai koefesien determinasi (R Square) sebesar 0,627 artinya bahwa pengaruh variabel kreativitas terhadap kesiapan bekerja sebesar 0,627 persen atau sebesar 62,7 persen artinya cukup besar dan selebihnya dipengaruhi oleh faktor lain sebesar 37,3 persen.

Hasil dari penelitian ini menunjukkan bahwa kreativitas memberikan pengaruh pada kesiapan bekerja siswa kelas XI dan XII jurusan BDP SMKN 1 Sinjai, sesuai dengan pendapat Slameto dalam skripsi Suryani $(2012,21)$ faktor-faktor yang mempengaruhi kesiapan bekerja siswa diantaranya adalah keterampilan dalam hal ini kreativitas, pengetahuan dalam hal ini didapatkan pada saat proses pembelajaran dikelas, motif, tujuan dan kondisi fisik, mental dan emosional. Sedangkan menurut Sukirin dalam Harjanto (2013) salah satu faktor yang mempengaruhi kesiapan bekerja yaitu pengalaman sebelumnya yang jika dihubungkan dengan siswa adalah pengalaman praktek kerja industri dan Class Alfamidi yang tujuan utamanya adalah membentuk kesiapan bekerja siswa siswa. 
Hasil penelitian ini sejalan dengan hasil penelitian yang dilakukan oleh beberapa orang. Pertama penelitian Maureen Evita Santi (2013) dengan judul Pengaruh Pengalaman Praktek Kerja Industri, Kompetensi Keahlian, dan Intensitas Pendidikan Kewirausahaan dalam Keluarga Terhadap Kesiapan Berwirausaha Siswa SMKN Yogyakarta, penelitian Maureen sejalan dengan penelitian ini yaitu pada indikator kompetensi keahlian, kompetensi keahlian yang dapat terbentuk melalui proses pembelajaran di kelas yang memuat mata pelajaran kompetensi keahlian jurusan BDP yang meliputi mata pelajaran pengelolaan usaha, penataan produk dan administrasi transaksi dan sejalan juga dengan indikator pengalaman praktek kerja industri.

Kedua dilakukan oleh Indra Abintya Rifai dan Sucihatiningsih (2016) dengan judul Pengaruh Pendidikan Kewirausahaan Dan Pelaksanaan Kegiatan Business Center Terhadap Minat Berwirausaha Siswa Kelas XI Jurusan Pemasaran SMKN 2 Semarang Tahun Ajaran 2015/2016, penelitian Indra membahas Business center yang sejalan dengan indikator ketiga dalam penelitian ini yaitu teori dan praktek Class Alfamidi. Pelaksanaan kegiatan Class Alfamidi dilakukan guna mempraktekan secara langsung apa yang selama ini diperoleh siswa di dalam kelas melalui teori-teori yang sudah diperoleh sebelumnya. Karena pada dasarnya kegiatan tersebut dimaksudkan untuk memberikan siswa pengalaman secara langsung bagaimana dunia usaha yang sesungguhnya dan kemandirian siswa dalam bekerja ketika lulus serta menumbuhkan jiwa wirausaha pada diri siswa. Ketiga Chrisna Tri Harjanto (2013) dengan judul "Pengaruh Minat Kerja Dan Prestasi Praktek Kerja Industri Terhadap Kesiapan Bekerja Siswa Kelas XII SMKN 1 Seyengan”. Dalam penelitian tersebut terdapat pengaruh praktek kerja industri terhadap kesiapan bekerja siswa yang sejalan dengan indikator ketiga dalam penelitian ini yaitu praktik kerja industri dengan kemampuan menerapkan teori yang didapatkan di kelas pada dunia kerja, yang sejalan dengan penelitian Nurbaya (2012) yang berpendapat bahwa seorang siswa yang telah memiliki pengetahuan yang cukup cenderung ingin mengaplikasikan apa yang telah diketahui, selanjutnya kemampuan memecahkan masalah yang dihadapi, dan pemahaman mereka tentang dunia kerja yang sebenarnya setelah pelaksanaan praktek kerja industri. Semakin banyak pengalaman yang diperoleh siswa maka siswa akan memiliki kesiapan yang tinggi karena pengalaman akan memberi bekal persiapan dalam menghadapi suatu yang baru dalam hal ini kemampuan mengisi lowongan yang tersedia. Pengalaman yang diperoleh siswa selama belajar di luar lingkungan sekolah yakni di dunia industri juga memberikan pengaruh dalam kesiapan berwirausaha. Berdasarkan Peraturan Pemerintah Republik Indonesia Nomor 19 Tahun 2005 tentang Standar Nasional Pendidikan Pasal 26 ayat 3 yaitu meningkatkan kecerdasan, pengetahuan, kepribadian, akhlak mulia serta keterampilan untuk hidup mandiri dan mengikuti pendidikan lebih lanjut sesuai dengan kejuruannya. Hidup mandiri yang dimaksud bukan hanya mengisi lowongan kerja di dunia industri tetapi juga bekerja mandiri menjadi wirausaha. Karena mengingat umur mereka yang masih muda dapat menjadi kekhawatiran tersendiri jika menekuni dunia usaha secara penuh. Sehingga lebih baik bagi para siswa jika mereka menekuni dunia industri berdampingan dengan dunia usaha agar memliki bekal kemampuan kelak dikemudian hari untuk dapat membuka peluang kerja bagi orang lain secara tepat. Menurut Umayah (2017) tingkat kesiapan bekerja siswa akan menentukan pilihan pekerjaan mereka setelah lulus. 


\section{KESIMPULAN}

Berdasarkan pembahasan dapat disimpulkan bahwa kreativitas berpengaruh positif dan signifikan terhadap kesiapan bekerja siswa dilihat dari 3 indikator yaitu proses pembelajaran, teori dan praktek Class Alfamidi, dan praktek kerja industri dengan menggunakan angket untuk menilai atau mendapatkan pendapat sendiri dari siswa. Berdasarkan uji regresi diketahui bahwa variabel kreativitas memiliki kontribusi sebanyak 62,7 persen terhadap kesiapan bekerja dan sisanya 37,3 persen dipengaruhi oleh faktorlain. Sedangkan berdasarkan uji deskriptif dapat disimpulkan bahwa kesiapan bekerja siswa belum maksimal yakni masih terdapat $22,2 \%$ siswa yang kesiapan bekerjanya masih rendah.

\section{DAFTAR PUSTAKA}

Badan Pusat Statistik. 2019. Keadaan ketenagakerjaan menurut tingkat pengangguran terbuka tahun 2015, 2016 dan 2018. www.bps.go.id (diakses agustus 2019).

Departemen Pendidikan Nasional. 1990. Peraturan Pemerintah Republik Indonesia No.29 Tahun 1990 Yang Memuat Amanat Tentang Pendidikan dan Pengembangan Kemampuan Siswa. Kemdiknas: Jakarta

Departemen Pendidikan Nasional. 2005. Peraturan Pemerintah Republik Indonesia Nomor 19 Tahun 2005 tentang Standar Nasional Pendidikan Pasal 26 ayat 3. Kemdiknas: Jakarta.

Harjanto, C, T. 2013. Pengaruh Minat Kerja Dan Prestasi Praktek Kerja Industri Terhadap Kesiapan Kerja Siswa Kelas Xii Smk Negeri 1 Seyegan. Skripsi Universitas Negeri Yogyakarta, 1-170.

Hendro. 2011. Dasar Dasar Kewirausahaan Panduan Bagi Mahasiswa untuk Mengenal, Memahami dan Memasuki Dunia Bisnis. Jakarta: Erlangga.

Ratnaningsih, I. Z., Kustanti, E. R., Prasetyo, A. R., \& Fauziah, N. 2017. Kematangan Karier Siswa SMK Ditinjau dari Jenis Kelamin dan Jurusan. Jurnal Humanitas, 2(13), 112-121.

Subijanto, S. 2012. Analisis Pendidikan Kewirausahaan di Sekolah Menengah Kejuruan. Jurnal Pendidikan dan Kebudayaan, 18(2), 163-173.

Sudarma, M. 2016. Mengembangkan Keterampilan Berfikir Kreatif. Jakarta: PT. Raja Grafindo Persada.

Suryani \& Hendryadi. 2013. Metode Riset Kuantitatif Pada Penelitian Bidang Manajemen dan Ekonomi Islam. Jakarta: Prenada Media Group.

Umayah, S. 2017. Pengaruh On the Job Training (OJT), Minat Kerja, dan Bimbingan Karir terhadap Kesiapan Kerja Siswa Kelas XII SMK Negeri 1 Batang. Skripsi Universitas Negeri Semarang. 1-62.

Wibowo, Y. 2018. Pengaruh Kemampuan Diri dan Faktor Lingkungan terhadap Keberhasilan Usaha Yang Dimediasi Oleh Motivasi Berwirausaha Pada Pada Usaha Mikro Jalan Malioboro Yogyakarta. Thesis Universitas Islam Indonesia. 